when in Berlin, in London, in Paris, man will not die of diphtheria, of typhoid fever, of scarlet fever, of cholera, or of tuberculosis any more than he dies in these cities to-day of the renom of snakes or of the tooth of wolves."

\section{SPASMUS NUTANS, OR THE NODDING SPASM.}

By GEORGE DICKSON, M.D. EDIN.,

FORMERLY RESTDENT MEDICAL OFFICER, EDINBURGH CITY POORHOUSE HOSPITAX, CRATGLOCKHAR'T.

THE following is a typical case of a somewhat rare disease - viz., spasmus nutans. The name "spasmus nutans" is somewhat misleading. Probably "spasmus oscillans" would be at once more descriptive and less confusing.

The patient, a boy aged one year, came under my care at Craiglockhart Poorhouse Hospital on Dec. 11th, 1893. No history was obtainable. On examination the child was found to be pale, but well nourished. There was only a slight appearance of rickets. There were two upper and two lower incisor teeth. The head was noticed to be constantly held inclined to the right side when the child was sitting up. In addition it shook from side to side in a way such as expresses dissent. The greatest excursion of the lateral movements was to the left, and there was a slight downward inclination, also to the left. The movements were not constant, but were induced or increased by excitement of any kind or by engaging the child's attention. Restraint of the movements caused marked discomfort. They entirely ceased during sleep and when the child was laid on his back. A day or two after admission horizontal nystagmus of the left eye was noticed. It also was only occasional, and was increased or induced by attempts at fixation, and markedly so by restraining the head movements. There was no impairment of vision or ocular movement, and the fundus oculi was healthy. The right pupil, however, was somewhat larger than the left. When looking at objects the child threw back his head, and, still keeping it inclined to one side, of necessity squinted at the object looked at instead of directing his gaze straight towards it. On Dec. 23rd the patient remained in statu quo. On Jan. 26th, 1894, the movements returned more markedly, and two teeth were observed to be cutting through the gums. On Jan. 29th there was slight return of nystagmus in the left eye, and slight nystagmus also of the right eye. About the middle of February another tooth cut through the gums and the nystagmus disappeared, the movements at the same time becoming less marked. On April 3rd the child to all appearance was quite well. In this case no treatment was adopted but the administration of cod-liver oil and attention to diet.

Since the above case came under my notice I have, through the kindness of Dr. John Thomson of Edinburgh, seen three others, and have been able from the books to collect full notes of twenty-three more, making twenty-seven in all. The literature on the subject is somewhat scanty. To Henoch of Berlin belongs the credit of having first drawn attention to the subject. In his text-book on Diseases of Children he gives in the first edition two cases and in the second edition four cases. In THE LANCET ${ }^{1}$ Dr. Stephen Mackenzie gives two cases (Harveian Society Reports). In St. Bartholomew's Hospital Reports ${ }^{2}$ two cases are recorded by Dr. Gee. In the Ophthalmic Society Reports ${ }^{3} \mathrm{Mr}$. Nettleship records what appears to be an example of spasmus nutans. In THE LANCET ${ }^{4}$ Dr. Hughlings Jackson mentions the affection in his address on the Relation of Ophthalmology to General Medicine, and suggests that it is akin to canine chorea. In the ophthalmic Review ${ }^{5}$ a case is quoted from Dr. Gordon Norrie of Copenhagen. The fullest account of the disease, however, will be found in THE LANCET, ${ }^{6}$ in which the late Dr. Hadden gave full notes of five cases and an analysis of twelve. In St. Thomas's Hospital Reports for 1892 Dr. Hadden recorded nine other cases. Kassowitz,

1 THe LaNCET, May 1st, 1886.

St. Bartholomew's Hospital Repurt, vol. xxii., 1886, p. 96.

3 Ophthalmic Society's Renorts, 1887, p. 76.

4 THE LANCE'I, Oct. 26th, 1889.

5 The Ophthalmic Review, 1888,355

6 THE LANCET, June 14th, 21st, and 28th, 1890 . in an untranslated paper ${ }^{7}$ mentions spasmus nutans, classifying it among the nervous symptoms of rickets. The following five symptoms of the disease may be noticed (1) head movements; (2) nystagmus; (3) petit mal (4) strabismus; and (5) a peculiar way of looking at objects. 'The first two are by far the most constant. Both movements and nystagmus are present in about 90 per cent. of the cases, but at certain stages, or even throughout its entire course, the affection may be represented by only one of these. During incidence one-most frequently nystagmus-appears before the other, and during subsidence the nystagmus generally persists longest. The head movements are most commonly a combination of shaking and nodding. Pure lateral movement is very uncommon, and pure nodding extremely rare. In frequency the movements are about 20 per minute. They cease during sleep and when the child is placed on his back. They are increased or, if absent, excited by engaging the child's attention. They are not increased or induced by covering the eyes. Whether moving or not, the head is generally held inclined to one side, and there is generally greater excursion of the movement to one or other side. Restraint of the movements causes marked un easiness. The nystagmus may be monocular or binocular, most commonly the latter. The nystagmic movements are very rapid, about 200 per minute. They are increased or induced by engaging the attention, and markedly so by laying the child on his back or by fixing the head. The nystagmus is only occasional, like the head movements. In direction it is most frequently horizontal, and only occasionally rotatory or vertical. Nystagmus of the eyelids sometimes occurs, and hippus has been noticed. With regard to petit mal, Dr. Hadden first drew attention to this fairly constant symptom. The child is simply observed to look vacant for a few seconds, and occasionally the head or the eyes, or both, deviate to one or other side. Strabismus is not nearly so common as the other symptoms. It may be constantly present or only occasionally. In some cases it is only noticed during an attack of petit mal. A peculiar way of looking at objects is nearly always observable. Dr. Hadden has happily described it as "looking out of the corners of the eyes." It is probably due to the head being held, when looking at objects, in that position in which its movements can best be restrained. The pupils are generally normal, but hippus has been noticed and occasionally temporary inequality of the pupils has been observed. The fundus oculi is always normal and the vision perfect. The general health is nearly always good. The diagnosis is comparatively easy. Eclampsia nutans - the salaam convulsion-is only confusing in name. In this the whole upper part of the body participates in a forward movement which is distinctly paroxysmal. The movements of spasmodic torticollis resemble slightly those of spasmus nutans. Cases represented by nystagmus alone might be mistaken for other forms of nystagmus until the eyes were examined and no ocular defect discovered. The prognosis is always favourable. In any given case it would be safe to say that recovery will take place before the child is two years of age, and that in all probability it will take place very much earlier. It is not the forerunner of epilepsy, and the after intelligence of the child is in no way impaired. As to treatment, the affection has a natural tendency to recover without drugs. Bromides are recommended by Dr. Hadden, Dr. Thomson has found benefit from antipyrin, and Kassowitz recommends anti-rachitic treatment (phosphorus).

Remarks. - In considering the etiology of spasmus nutans it is evident that, while sex has probably no influence, age is a factor of the first importance. A comparison of the cases shows that 50 per cent. occurred between six and twelve months; 15 per cent. were under six and 15 per cent. over twelve months of age. The youngest was that recorded by Norrie, where the disease was noticed shortly after birth. Although Kassowitz looks upon the affection as due to rickets, this occurs in such a small proportion of the cases that it cannot be looked upon as more than an occasional predisposing cause. Convulsions, either as a personal or family tendency, are somewhat uncommon. Falls on the head are recorded in six or seven of the cases, the affection being noticed immediately afterwards. Dr. Hadden suggests that they may be more the result than the cause, being actually attacks of petit mal. It is possible also that anxious mothers, looking out after a fall for consequent mischief, have their attention first drawn to symptoms already existent. Dentition is, 
without doubt, an important causative factor. The disease is one peculiar to the dentition period. Moreover, Dr. Thomson had a case where the symptoms began at three months, dentition also beginning at this abnormally early period. That it is not the only etiological factor involved is shown by the fact that the disease may appear when dentition is not active-e.g., two cases under one month. The nystagmus which occurs in coal-miners presents a somewhat curious analogy to spasmus nutans. In miner's nystagmus head movements occasionally occur in bad cases, and attacks of petit mal have been recorded. ${ }^{8}$ 'The occurrence together of head and eye movements would point to a very intimate connexion between the cerebral centres presiding over these movements. This is further suggested by the close inter-relation which subsists between the two in a state of health, and by the compensatory action of either in certain paralytic conditions of the other-e.g., ophthalmoplegia externa. Moreover, it is well known that there is a special frontal centre presiding over the combined movement of head and eyes. In this connexion it is interesting to observe the almost invariable correspondence in direction of head-and-eye movements in spasmus nutans. Out of seventeen cases that can be compared this correspondence was present in fifteen. This includes one case where the inystagmus was vertical in one eye and horizontal in the other, the head movements being combined nodding and shaking, and a still more interesting and suggestive case where the nystagmus was generally horizontal, occasionally rotatory or vertical, and in which the head movements were usually shaking, but occasionally nodding. The disease is probably due to an instability of the ultimate elements of the brain substance in the region of the centre involved. This instability further evidences itself.by the frequent occurrence - of petit mal. Dentition must be looked upon as by far the commonest exciting cause, but it is probable that any other reflex irritation would-other things being equal-produce the same effect. In one of my cases, where there was no appearance of dentition, a probable reflex cause was a large irritable patch of eczema capitis, the cure of which was followed by subsidence of the symptoms. It must be remembered that about this period the whole nervous system is in a state of great irritability and instability, and it is scarcely surprising that the highly complicated mechanism involved in what are the first attempts at coördinated action tends to get out of gear from trivial causes.

I have to acknowledge my indebtedness to Dr. Edward Carmichael, visiting medical officer to the Edinburgh City Poorhouse, for much kindness in supplying me with literature and many valuable suggestions.

\section{LAPAROTOMY IN TUBERCULOUS PERITONITIS.}

BY GEORGE E. WHERRY, F.R.C.S. ENG.,

SURGEON TO ADDENBROOKR'S HOSPITAL, CAMBRIDGE; LECTURER ON SURGERY, INIVHRSITY OF CAMBRIDGE.

LAPAROTOMY and douching of the peritoneal cavity are proceedings too often described as " heroic,"and are either never tried at all or only used as a last resource. One of the most striking cases of recovery I ever witnessed was that of a patient sent to Addenbrooke's Hospital under my care as suffering from obstruction of the bowel, vomiting and complete constipation being the prominent symptoms. It was judged to be a case of tuberculous peritonitis with many adhesions. The greatest success followed an operation in which purulent lymph and fluid were washed out of the abdominal cavity by free warm douches. There were many adhesions found, but no constricting band. A case quoted by Mr. Knaggs is similar. ${ }^{1}$ As a more deliberate proceeding, and before the patient is in immediate danger, the operation may prove of great advantage. The following case is an example in which there existed disease in the chest, as well as most serious tuberculous peritonitis, with an unusual amount of fluid in the peritoneal cavity. Abdominal incision and washing out the peritoneal cavity gave excellent results.

A young woman aged nineteen years was sent for treatment

'8 Oglesby: Brain, 1881, p. 160

1 Transactions of the Clinical Sociely of London, vol, xxi. under my care in Addenbrooke's Hospital by Mr. De Lisle in January, 1895, when it was noted that she had a good family history and had a healthy past life, not often ailing except for amenorrhœa and anæmia. During the past six months she had been invalided, and for the last three months had had a dry cough, with pain in the right side, which lasted three weeks and was followed by shortness of breath. 'The abdomen had gradually been growing bigger during about nine months. There was no blood spitting or night sweats. She was a fair girl with good teeth, but had been losing flesh lately. In the chest there were exaggerated breathing sounds on the left side. The right side was dull throughout, and breathing was diminished. There was no pectoriloquy. At the apex there was an occasional crepitus or crackle due to friction. There was no cough or expectoration. The abdomen was distended, bulging in the flanks. The dulness in the flanks extended half-way to the umbilicus, which varied with the position of the patient. There was a fluid thrill. No tumour was felt and no friction was audible. Pain and tenderness were very slight. The bowels were regular. The catamenia were absent. The specific gravity of the urine was 1020, acid; it contained phosphates, with distinct albumin. At the end of January Dr. Latham kindly consulted with me about her condition. The lung signs were most serious, and the circumference of the abdomen at the umbilicus was thirty-five inches. The patient grew decidedly worse, the abdomen painfully tense, and on Feb. 12th an operation was performed under an anæsthetic. Through a median abdominal incision (three inches) fifteen pints of fluid were evacuated. There was no evident pus or lymph; the whole of the peritoneal lining of the abdomen and bowels withm sight or touch was thickly studded with tubercles varying in size from a pin's head to a pea. The right ovary felt like a nutmeg grater; no smooth surface could be found anywhere in the abdominal or pelvic cavity. Warm boric douching was used, and the wound was closed with sutures and covered as after ovariotomy. It was examined on the twelfth day and found to be healed, the patient's condition having already improved. The temperature, which had been usually up to $100^{\circ} \mathrm{F}$. in the evening, became uniformly normal from the date of the operation. A certain amount of fluid collected again, but the patient improved so far that she could leave the hospital on March 23rd. Mr. De Lisle wrote to me on June 29th as follows: "I have delayed answering your letter, waiting to see what the result of time, following your directions, would be in the case of the patient upon whom you operated. I am extremely pleased to be able to tell you that the result is eminently satisfactory. Up to May the fluid in the abdominal cavity did not seem to lessen, and I was afraid I should have to send her back to you. With the advent of the fine warm weather early in May a marked improvement took place; the fluid seemed rapidly to disappear, sweating ceased, the cough lessened, and she began to gain flesh and strength. She is now her normal size, has no cough, has walked as much as ten miles in a day, and has gained weight. In fact, she describes herself as feeling "quite well." " on Sept. 3rd her progress to recovery was complete. She was 10 st. $3 \mathrm{lb}$. in weight, there being no active lung symptoms. The size of the abdomen was normal. She did her work, walked, danced, and led the ordinary healthy life of a girl of her age full of vitality.

Mr. Holmes ${ }^{2}$ gives the experience of St. George's Hospital in seven years as three operations of laparotomy for tuberculous peritonitis and two deaths. The fatal cases were complicated in one instance by a band constricting the bowels and in the other by pneumonia. There was in the case I have just related an improvement in the general bealth after my operation which permitted an arrest of activity in the abdominal disease. We must not expect that patients will be cured when all the cavities of the body are full of tubercle, but every chance should be given to surgical procedure as a most powerful remedial agent in tuberculous peritonitis. It will be, perhaps, found that a case with a large quantity of fluid is most suitable for laparotomy; but this may be only because the fluid collects more in the earlier stage of the disease and adhesions mat together the bowels in more advanced cases. By laparotomy the fluid is thoroughly drawn off, and the tension is reliered, and whether douching is more than accessory to drainage it is difficult to say. Certainly tapping the abdomen alone makes 